\title{
CONSUMO DE ENERGIA ELÉTRICA NAS FAVELAS E A TRANSFORMAÇÃO DE "CONSUMIDORES EM CLIENTES"1
}

\author{
FRANCESCA PILO,2 \\ Universidade de Amsterdã
}

\begin{abstract}
Resumo: O processo de regularização de acesso aos serviços de energia elétrica em aglomerados informais é frequentemente descrito como uma "transformação de consumidores em clientes" (USAID, 2009). Na maior parte dos casos, tal transformação consiste em implementar medidas de redução das perdas comerciais e redefinir a relação comercial através de medidas técnicas, comerciais e de eficiência energética. Dentro do contexto das transformações políticas nas favelas do Rio de Janeiro onde foram instaladas as UPPs (Unidades de Polícia Pacificadora), este artigo explora o processo de regularização da energia elétrica, concentrando-se nos aspectos das ações de eficiência energética implementadas pela companhia de distribuição do serviço, a Light. O objetivo principal deste artigo é mostrar como esta forma de reconfiguração de infraestrutura é implementada através de lógicas comerciais que, por sua vez, têm consequências na maneira como as medidas de economia de energia são promovidas. Inicialmente o artigo apresenta dois diferentes corpus de literatura cuja articulação permite uma compreensão da relação entre infraestrutura, práticas de consumo e políticas públicas de eficiência energética. Em seguida, o artigo propõe uma análise das ferramentas usadas pela companhia e das percepções das famílias. $\mathrm{O}$ artigo argumenta que as medidas adotadas pela companhia de distribuição de eletricidade aparecem para enfraquecer a compreensão dos consumidores sobre seu próprio consumo. $\mathrm{O}$ artigo destaca então alguns limites de uma abordagem comercial para a economia de energia e as contradições de sua política.
\end{abstract}

Palavras-chave: Favelas. Eficiência energética. Infraestrutura. Práticas de consumo. Consumidor. Cliente.

\footnotetext{
${ }^{1}$ Versão traduzida do inglês para o português. Versão original: Pilo' F. (2016). Rio de Janeiro: Regularising energy consumption in favelas through reshaping consumers into customers. In: Luque, A.; Silver, J. (Dirs.). Energy, Power and Protest on the Urban Grid. Geographies of the Electric City. London: Routledge, p. 67-85.

${ }^{2}$ Doutora pela Universidade Paris-Est e Universidade Federal Fluminense. Pesquisadora de pós doutorado na Universidade de Amsterdã, Department of Human Geography, Planning and International Development.
} 


\title{
ELECTRIC ENERGY CONSUMPTION IN FAVELAS AND THE RESHAPE OF "CUSTOMERS IN COSTUMERS"
}

\begin{abstract}
The process of regularization of access to electricity services in informal settlements is often described as a "transformation of consumers into customers". In most cases, such a transformation is to reduce commercial losses, and redefine poor commercial relationship through technical, commercial and energy efficiency measures. Within the context of the political changes in the favelas of Rio de Janeiro where the UPPs were installed (Pacifying Police Units), this article explores the process of electricity regularization, focusing on the aspects of energy efficiency measures implemented by the distribution company service. The main purpose of this article is to show how this form of infrastructure reconfiguration is implemented through commercial logics, which in turn have consequences in the way of energy saving measures are promoted. Firstly, the article presents the articulation of two different body of literature that allow an understanding of the relationship between infrastructure, consumer practices and public policies for energy efficiency. Secondly, the article proposes an analysis of the tools used by the company and the perceptions of families. The paper argues that the measures adopted by the electricity distribution company appear to weaken consumer understanding about their own consumption. The article highlights some limits of a commercial approach to saving energy and contradictions of its policy.
\end{abstract}

Keywords: Favelas. Energy Efficiency. Infrastructure. Consumer practices. Consumer. Costumers.

\section{Introdução}

O processo de regularização de acesso aos serviços de energia elétrica em aglomerados irregulares nas cidades da América do Sul é frequentemente descrito como uma "transformação de consumidores em clientes" (USAID, 2009). Na maior parte dos casos, tal transformação consiste em implementar medidas de redução das perdas comerciais $^{3}$ e redefinir a relação comercial através de medidas técnicas, comerciais e de eficiência energética. No Brasil, estes tipos de projetos surgiram a partir dos anos 1990 no contexto de reestruturação e privatização do setor de energia elétrica compreendendo a introdução de operadores privados no segmento de distribuição do serviço. Com efeito, essas reformas contribuíram amplamente para uma redefinição da maneira como o acesso informal à energia elétrica é gerenciado pelas distribuidoras. Desde este período, diminuir as perdas comerciais torna-se um objetivo prioritário das distribuidoras de energia elétrica, através de projetos de regularização de energia elétrica. Na cidade do Rio de Janeiro, essas medidas são particularmente implementadas em favelas, locais onde vivem quase $20 \%$ da população da cidade (1.400.000 de pessoas, de acordo com o censo nacional de 2010). Apesar de isso poder parecer um processo puramente econômico, trata-se, na verdade, de uma eminente intervenção política na cidade.

\footnotetext{
${ }^{3}$ No setor da energia elétrica as perdas comerciais, também chamadas perdas não técnicas, correspondem às perdas associadas à distribuição de energia elétrica tais como erros de medição, erros no processo de faturamento, unidades consumidoras sem equipamento de medição, manipulação dos medidores etc. Mais geralmente, as perdas comerciais correspondem à energia consumida que não é faturada. Esse tipo de perda está diretamente associado à gestão comercial da distribuidora.
} 
O cenário político mutante do Rio de Janeiro incessantemente remodela os contornos das dimensões políticas e governamentais da regularização do acesso à energia elétrica nas favelas (PILO', 2015). A recepção dos chamados megaeventos na cidade do Rio de Janeiro atualizou a questão da segurança pública na agenda política do governo do estado, tendo em vista o controle de um grande número de favelas por diferentes facções ligadas ao tráfico de drogas desde o final da década de 1980. Desde 2008, algumas favelas tornaram-se lugares-chave da ação governamental, primeiramente através de um novo programa de segurança pública do estado, que permanentemente instala forças armadas policiais nesses locais, utilizando-se das UPPs (Unidades de Polícia Pacificadora): 38 unidades do tipo foram instaladas até 2016. Tal processo reconfigura parcialmente o contexto de atuação da companhia de energia elétrica, pois a presença das UPPs é considerada pela operadora como uma oportunidade para desenvolver os projetos de regularização do serviço em um ambiente física e economicamente mais seguro.

Dentro do contexto dessas grandes transformações políticas, este artigo explora o processo de regularização da energia elétrica, concentrando-se nos aspectos das ações de eficiência energéticas implementadas pela companhia de distribuição do serviço na cidade do Rio de Janeiro, a Light. Além de um processo estritamente técnico ou comercial (focado em instalações de medidores de energia e reparo de redes, ou ainda em sistemas de coleta de conta de luz), a regularização do serviço de energia elétrica também envolve ferramentas específicas para promover a eficiência energética, com uma atenção particular ao padrão de consumo dos clientes. Este artigo procura compreender a relação entre a mudança de infraestrutura e a política de eficiência energética em um contexto em que a construção de uma relação comercial apresenta múltiplos desafios, como aqueles encontrados nas favelas. $\mathrm{O}$ objetivo principal do trabalho é mostrar como esta forma de reconfiguração de infraestrutura é implementada através de lógicas comerciais que, por sua vez, têm consequências na maneira como as medidas de economia de energia são promovidas.

Para este propósito, a primeira parte do texto articula dois diferentes corpus de literatura, permitindo uma compreensão da relação entre infraestrutura, práticas de consumo e políticas públicas de eficiência energética. A segunda parte fornece uma narrativa que descreve as diferentes políticas de gerenciamento do acesso à rede de energia elétrica nas favelas do Rio. A este panorama histórico segue-se a descrição do contexto regulatório, dos objetivos e implementações da eficiência energética nas favelas. $\mathrm{O}$ artigo se encerra com uma análise das ferramentas sociotécnicas usadas pela Light na favela Santa Marta, localizada no bairro de Botafogo, zona sul do Rio de Janeiro, a fim de estimular as famílias a economizar energia. O estudo apoia-se em um trabalho de campo realizado entre 2010 e 2011, baseado em entrevistas semiestruturadas com 25 famílias e com funcionários da companhia de distribuição de energia elétrica, em particular com aqueles responsáveis pelo programa de economia de energia. Conjugando as análises das ferramentas usadas e das 
percepções das famílias, a última parte explora os limites de uma abordagem comercial para a economia de energia e as contradições de sua política. $\mathrm{O}$ artigo argumenta que as medidas adotadas pela companhia de distribuição de eletricidade aparecem, ao mesmo tempo, para enfraquecer a compreensão dos consumidores sobre seu próprio consumo. O artigo destaca então alguns limites de uma abordagem comercial para a economia de energia e as contradições de sua política.

\section{Conectando infraestruturas políticas e práticas de consumo}

Os estudos de infraestrutura exploraram o papel destes sistemas sociotécnicos nas sociedades urbanas a partir de uma grande variedade de perspectivas teoréticas (MCFARLANE; RUTHERFORD, 2008). Uma parte significativa deste corpus literário enfocou a onda de privatização em serviços de infraestrutura que começou nos anos 1990, com uma análise centrada nas transformações decorrentes em cidades do hemisfério sul e do hemisfério norte (GRAHAM; MARVIN, 2001; JAGLIN, 2005; COUTARD, 2008). No caso das cidades do hemisfério sul, o termo "arquipélagos", cunhado por Karen Bakker (2003), foi bastante usado para descrever a multiplicidade de formas de prestação de serviço encontrada em tais lugares. Bakker contrasta a noção de arquipélagos com o termo "rede", argumentando que o anterior representa melhor o cenário da infraestrutura urbana do hemisfério sul. Enquanto Bakker fala sobre a presença de uma gama de serviços "fora da rede", a metáfora do arquipélago mostra-se útil ao apontar para as disparidades espaciais na qualidade e na prestação de serviço no Rio de Janeiro. De fato, mesmo se a cobertura da rede de energia elétrica é considerada como universal na cidade, é possível identificar uma diferenciação espacial na qualidade dos serviços nas favelas subsequente a uma intervenção mínima da empresa na melhoria das condições técnicas da rede. O controle territorial das favelas por grupos ligados ao tráfico de drogas é apresentado pela empresa como um elemento que justifica o tratamento diferenciado na prestação de serviço, invocando a difícil atuação da companhia nessas áreas. Então, o processo de territorialização das favelas por grupos ligados ao tráfico de drogas, definido por alguns autores como um vetor de fragmentação sociopolítica do tecido urbano (LOPEZ DE SOUZA, 2005), tem repercussões importantes na gestão do serviço nessas áreas. Assim, fragmentação sociopolítica e diferenciação diferenciação da/na qualidade do fornecimento da energia elétrica (PILO', 2016a) se sobrepõem no processo de diferenciação espacial na cidade.

A literatura sobre a reconfiguração da infraestrutura fornece quadros teóricos e analíticos úteis para a análise de infraestruturas enquanto ferramentas políticas capazes de modificar as relações de poder, de produzir (ou reduzir) desigualdades, de governar a cidade (LORRAIN, 2011). Análises históricas da distribuição de água em Jakarta (KOOY; BAKKER, 2008) e das infraestruturas de esgoto em Mumbai 
(MCFARLANE, 2008) mostram como, ao gerar noções associadas a ideais de modernidade, moralidade, espaço público e cidadania, o desenvolvimento de infraestruturas acaba tornando-se um instrumento para a construção social da desigualdade (MCFARLANE; RUTHERFORD, 2008). Em sua análise de programas de acesso à água na Colômbia, Furlong (2012) aprofunda o debate acerca do papel político das infraestruturas, integrando os usuários e suas práticas na análise de novas formas de configuração de infraestruturas. De maneira similar, este artigo examina a interação entre uma reconfiguração de infraestrutura e as supostas implicações na redefinição das práticas de consumo dos usuários.

A segunda parte da literatura estabelece uma conexão entre práticas de consumo e políticas públicas cujo objetivo é encorajar usuários a alterar seus hábitos de consumo em direção a supostas práticas "sustentáveis". A multiplicação de políticas públicas elaboradas para alterar os hábitos de consumo dos usuários - a princípio, por motivos ambientais - resultou, dentro das ciências sociais, em um número significativo de estudos que exploraram a conexão entre políticas, instrumentos para eficiência de energia e hábitos de consumo, ainda que poucos desses estudos tenham tido como foco cidades do hemisfério sul (ver ZÉLEM, 2010; JAGLIN; SUBRÉMON, 2012). Ao examinar as políticas de eficiência energética, essa literatura revela a importância central de uma análise detalhada das práticas de consumo, revelando, em seguida, as lógicas de mudança ou resistência à transformação dos usos da energia. Tal literatura também mostra como os usuários são um grupo bastante heterogêneo e por isso devem ser segmentados, à medida que os instrumentos políticos para encorajar mudanças nos hábitos de consumo são redefinidos. Assim, políticas a respeito do que se intitulam os "ecogestos", uma abordagem amplamente implementada em campanhas de informação, tanto no hemisfério norte quanto no hemisfério sul, geraram fortes críticas dentro das ciências sociais. De acordo com Jaglin e Subrémon (2012, p. 1), a relevância relacionada aos ecogestos é demasiado simplista, uma vez que assume uma "virtuosa convergência de pequenas ações individuais e isola práticas de seu invólucro de rotinas, hábitos e também obrigações". De fato, um número substancial de estudos em antropologia já demonstrou que o uso de energia é afetado por uma multiplicidade de fatores sociais e culturais (para uma avaliação mais ampla, ver SUBRÉMON, 2011) e que o consumo "é costumeiro, governado por normas coletivas e realizado em um mundo de coisas e de sistemas sociotécnicos que vêm estabilizando efeitos em rotinas e hábitos" (SHOVE, 2003, p. 9). À luz destas realidades, a abordagem através dos ecogestos tem uma eficácia limitada. Ao contrastar tais enfoques, um corpus emergente de literatura acadêmica aponta para uma conexão mais direta entre infraestruturas e práticas sociais, sem necessariamente focar-se em um entendimento aprofundado do hábito individual. Shove e Walker (2010, p. 476), por exemplo, argumentam em favor de ir além de uma análise focada na introdução de novas tecnologias desenvolvidas para acompanhar os usuários para modos de vidas mais sustentáveis e propõem que deve 
haver interesse pelas práticas sociais - em vez de indivíduos, grupos sociais etc. para conceituar transições e inovações nas práticas quotidianas.

As seções restantes deste capítulo se apoiam na conexão entre as duas literaturas citadas para abordar a pergunta seguinte: como uma reconfiguração de infraestrutura com o objetivo de formalizar "arquipélagos" informais tem relação com práticas de consumo? Para responder a esta pergunta, nossa análise se interessa pelas interações entre diversas ferramentas, que têm por objetivo transformar consumidores em clientes, e a apropriação de tais ferramentas por residentes das favelas do Rio de Janeiro.

\section{A política de regularização do serviço de energia elétrica nas favelas do Rio de Janeiro}

Em 1979, o primeiro programa oficial de eletrificação das favelas no Rio de Janeiro foi executado sob o nome de "programa de eletrificação de interesse social" (Light, 1980). Introduzido pela empresa de distribuição de energia elétrica do Rio de Janeiro, a Light, controlada pelo governo federal à época, o programa conectou oficialmente a maioria das favelas da cidade à rede pública. Com a instalação de medidores de energia individuais em cada habitação, os moradores das favelas passaram a ser formalmente reconhecidos como usuários - exatamente como os demais habitantes da cidade. Foi uma realização política e social substancial, tendo em vista que, até então, a eletrificação oficial das favelas era proibida por causa da definição desses locais como espaços ilegais para os poderes públicos. Com efeito, a instalação das redes de serviços públicos era considerada um reconhecimento de fato das favelas, tendo implicações importantes em termos de direitos pelos moradores, e por isso os poderes públicos sempre evitaram até então oficializar o acesso (ver PILO', 2015; GONÇALVES SOARES; PESSANHA CABRAL; MORORÓ MARTINS, 2016, para uma perspectiva histórica sobre o acesso à energia elétrica nas favelas).

Como resultado, a cobertura de eletricidade no Rio de Janeiro parece ter se tornado universal. Por esta razão, por pelo menos quinze anos, profissionais que trabalhavam na área referiram-se a intervenções da Light na rede de eletricidade como uma regularização de acesso ao serviço, e não de eletrificação. A mudança dos termos, de eletrificação a regularização, não é apenas uma questão semântica, pois revela as transformações nas políticas de acesso à energia elétrica no contexto de reformas mais amplas do setor de energia elétrica. Com efeito, a origem desta mudança de sentido remonta aos anos 1990, quando o governo federal inicia um processo de reestruturação e liberalização no setor da eletricidade e introduz operadores privados no segmento da distribuição do serviço.

A empresa francesa Electricité de France (EDF) assumiu o controle da maior 
parte da Light em $1996^{4}$, no Rio de Janeiro. Se a cobertura da rede na sua área de concessão ${ }^{5}$ era considerada como universal, quase 400 mil habitações não possuíam medidores e não eram formalmente clientes da Light. Regularizar o acesso à energia elétrica foi então um objetivo prioritário da empresa no seu plano de desenvolvimento comercial. Com este fim, entre 1999 e 2002, a Light implementou o primeiro programa de regularização de energia elétrica: o Programa de Normalização de Áreas Informais, que cobria 240 favelas e regularizava as relações comerciais para 260 mil clientes.

Apesar do programa extensivo, nos anos 2000, as perdas comerciais continuaram sendo elevadas. No contexto das favelas, a presença de grupos ligados ao tráfico de drogas é apresentada pela empresa como um dos maiores obstáculos às suas ações, gerando implicações importantes na definição das suas práticas de gestão. Essas favelas são então identificadas e definidas pela empresa como "áreas de risco", o que sustenta uma intervenção mínima na melhoria das condições do serviço e explica parcialmente, conforme exposto anteriormente, a grande precariedade do serviço nessas áreas. É interessante ressaltar como, no contexto de um serviço público comercializado, a definição das favelas como "áreas de risco" articula duas dimensões: o "risco" físico, para os agentes da empresa entrarem nas favelas, e o "risco" econômico, pois a durabilidade das medidas de regularização do serviço nesses contextos é considerada fraca. Essas duas dimensões se sobrepõem na construção da categoria "favela", tendo implicações que vão além das representações sociais e afetam diretamente a forma como o serviço é providenciado.

A perspectiva de sediar grandes eventos internacionais no Rio de Janeiro (Copa do Mundo e Olimpíadas, entre outros) contribuiu diretamente para a mudança da gestão da energia elétrica nas favelas. Em um contexto de internacionalização da cidade, o governo do Estado estabeleceu uma política de segurança pública através da manutenção da presença permanente da polícia em certas favelas. As UPPs foram instaladas nas favelas a partir de 2008, com o declarado objetivo de restabelecer um controle territorial por parte do estado. A presença da polícia estabeleceu novas condições de ação para as autoridades do governo e para os operadores de serviços urbanos e demais atores privados. As UPPs foram consideradas uma oportunidade de regularizar as relações comerciais e não comerciais dentro das favelas. A Light começou então a regularizar o serviço em diferentes favelas articulando medidas técnicas (reforma da rede e instalação dos medidores), medidas comerciais e medidas de eficiência energética. Neste contexto, é importante ressaltar que o número de clientes já registrados na companhia antes da regularização do serviço podia variar de maneira significativa de uma favela a outra. A título de exemplo, o

\footnotetext{
${ }^{4}$ Em 2006, 78,4\% da Light foi comprada pela Rio Minas Energia Participações S.A.

${ }^{5}$ Define-se como área de concessão os limites geográficos na prestação dos serviços e distribuição de energia elétrica definidos nos contratos de concessão de cada empresa.
} 
número de clientes registrados na favela de Chapéu Mangueira, situada no Leme, zona sul do Rio de Janeiro, cresceu de 430 para 600 após a introdução do processo de regularização do serviço em 2010. Na favela vizinha, Babilônia, o mesmo processo levou a um aumento de clientela de 414 para 1.017 (KELMAN, 2012) ${ }^{6}$. Porém, independentemente do número de clientes registrados, as perdas comerciais eram geralmente elevadas: $56 \%$ no Chapéu Mangueira e $73 \%$ no Babilônia, por exemplo. A regularização do serviço trouxe então uma mudança significativa na forma de acessar o serviço para esses moradores.

Neste novo contexto, focalizaremos a atenção nas medidas de eficiência energéticas. A próxima seção apresentará um contexto geral do programa de eficiência de energia, assim como os atores envolvidos.

\section{O programa de eficiência energética nas favelas: "obrigações regulamentares" e atividade comercial}

\section{Um papel proativo do Estado na promoção da eficiência energética}

A energia elétrica representa um recurso crucial para o desenvolvimento socioeconômico do Brasil. Desde os anos 1980, a política de eficiência energética tem sua importância na agenda nacional, devido a diversos fatores. Em primeiro lugar, a rápida industrialização e o crescimento econômico alto e contínuo, juntamente com a melhoria no padrão de vida, contribuíram substancialmente para uma profunda mudança no uso de eletricidade, apesar das disparidades econômicas significativas entre as regiões e entre as áreas rural e urbana. Isso se traduziu em um rápido crescimento na taxa de conexão à rede de eletricidade: entre 1980 e 2000, a proporção de moradias conectadas passou de $68 \%$ para $93 \%$ (IBGE, 2000). De maneira similar, o consumo total de eletricidade cresceu em $250 \%$ entre 1975 e 2000, e o consumo individual médio cresceu 60\% (GELLER, 2003, p. 188). Em segundo lugar, nos anos 1980, a deterioração das finanças no setor da eletricidade forçou o governo federal a contrair empréstimos com agências multilaterais de financiamento ao desenvolvimento, em condições que levaram o setor a considerar mais seriamente as questões ambientais e a necessidade de gerenciar a demanda de eletricidade (DE GOUVELLO; JANNUZZI, 2002).

Em 1985, o governo introduziu o PROCEL (Programa Nacional de Conservação de Energia Elétrica), o primeiro programa de gerenciamento de demanda de energia elétrica do país. Porém, conforme De Gouvello e Jannuzzi, a partir dos anos 1990, o PROCEL torna-se cada vez mais sujeito à optimização da oferta (DE GOUVELLO;

\footnotetext{
${ }^{6}$ Deve-se, contudo, enfatizar que estes números divergem daqueles do censo de 2010. De acordo com o censo de 2010, Chapéu Mangueira tinha 401 domicílios, e Babilônia, 777, números que são menores que os declarados pela companhia de energia elétrica.
} 
JANNUZZI, 2002). O programa baseava-se em medidas primordialmente desenvolvidas para aprimorar sistemas de produção e de transporte da energia, e, a partir de 1993, foi criado o programa selo PROCEL, que tem como objetivo principal orientar os consumidores na escolha de compra dos aparelhos elétricos mais eficiente (DE GOUVELLO; JANNUZZI, 2002). Além desses programas, a partir dos anos 2000 o governo federal exigiu que as companhias de distribuição também contribuíssem para o gerenciamento da demanda de energia elétrica. A Lei Federal n. 9.991/2000 exigia das companhias de distribuição de energia elétrica o investimento de ao menos $0,5 \%$ da receita operacional anual tanto para pesquisa e o desenvolvimento $(\mathrm{P} \& \mathrm{D})$ como para programas de eficiência energética na oferta e no uso final da energia (PEE).

Esses programas podem beneficiar uma grande variedade de consumidores, incluindo autoridades locais e serviços públicos, os setores de comércio e de serviços, a indústria, o setor residencial, áreas rurais e comunidades de baixa renda. Dentro desta gama, as comunidades de baixa renda são consideradas como um grupo prioritário e ao menos $60 \%$ do investimento deve ser direcionado aos usuários residentes de tais áreas ${ }^{7}$. A Agência Nacional de Energia Elétrica (ANEEL) ${ }^{8}$ monitora o comprimento dessas metas. Como nota Jannuzzi (2002), o impacto ambiental dessas iniciativas é apenas um dos aspectos envolvidos no gerenciamento da demanda de energia elétrica. A intervenção também é pensada para se chegar a uma maior confiabilidade na rede de energia elétrica, a cortes de gastos associados à produção de eletricidade, à transmissão e à distribuição, além de redução de custos para usuários finais. Nesse cenário, medidas desenvolvidas para promover a eficiência energética são combinadas ao objetivo de se reduzir a pobreza, um objetivo político até pouco tempo de primeira importância no Brasil, um país marcado por significativas disparidades socioeconômicas e espaciais.

\footnotetext{
${ }^{7}$ A aplicação dos recursos destinados a programas de eficiência energética tiveram várias mudanças legislativas ao longo dos últimos anos. No momento de nossa pesquisa, os Programas de Eficiência Energética (PEEs) destinavam-se a "comunidades de baixa renda"; logo, todos os usuários residenciais em tais áreas eram beneficiários em potencial. Contudo, após a aprovação da Lei n. 12.212/2010, o grupoalvo foi modificado. Quando a lei obteve mais força, em 2011, apenas os usuários dentro do critério para acesso à tarifa social subsidiada teriam direito ao programa. Uma lei sucessiva, Lei n. 13.280/2016, define que as concessionárias de distribuição de energia elétrica "poderão aplicar até $80 \%$ (oitenta por cento) dos recursos de seus programas de eficiência energética em unidades consumidoras beneficiadas pela Tarifa Social de Energia Elétrica, em comunidades de baixa renda e em comunidades rurais" (art. 5, Lei n. 13.280/2016).

${ }^{8}$ A Agência Nacional de Energia Elétrica (ANEEL) foi criada em 1996 durante o primeiro mandato do presidente Fernando Henrique Cardoso como agência reguladora do setor da energia elétrica no contexto mais amplo de reestruturação e liberalização do setor. Sua missão é de regular e fiscalizar a produção, transmissão e comercialização de energia elétrica e, mais amplamente, controlar a conformidade do comportamento dos atores do setor em conformidade com as políticas e diretrizes do governo federal.
} 


\section{Os atores do "Comunidade Eficiente"}

De acordo com as obrigações legais em nível nacional, cada companhia de distribuição de eletricidade dirige programas de eficiência energética em comunidades de baixa renda. Na Light, o programa de eficiência energética chamado de "Comunidade Eficiente" - passa a ser implementado a partir de 2002, beneficiando mais de 260 mil usuários em 272 comunidades (LIGHT, 2011). O programa promove dois tipos de medidas: um componente técnico, que consiste em substituir gratuitamente refrigeradores e lâmpadas ineficientes por eletrodomésticos de acordo com os padrões nacionais de eficiência energética; e um componente que a distribuidora define como "educacional", que consiste em mostrar aos clientes como adotar práticas mais moderadas de consumo de energia, a fim de evitar o desperdício. Essas duas medidas são consideradas complementares na promoção de economias de energia no consumo residencial de eletricidade.

$\mathrm{Na}$ época do nosso estudo, a implementação do programa "Comunidade Eficiente" era terceirizada por uma companhia com sede em São Paulo, cuja especialidade era a implementação de projetos sociais em comunidades de baixa renda. Apesar de algumas vezes descrita como sem fins lucrativos por atores locais, a organização é registrada como uma iniciativa comercial. A organização envolve-se particularmente com iniciativas de "educação ao uso eficiente" de energia elétrica, implementadas por agentes da comunidade. Tais agentes trabalham com usuários, baseando-se em um manual educacional de trabalho distribuído pela Light que, basicamente, ensina noções de eficiência de energia - assim como suas implicações econômicas -, explicando a tabela de preços da companhia e os métodos usados para calcular o consumo de energia de uma moradia. Além disso, desde 2006, a Light tem trabalhado em parceria com o Comitê para Democratização da Informática (CDI), uma organização sem fins lucrativos cuja missão é "fortalecer comunidades de baixa renda através do uso de tecnologias de informação e comunicação" (ONG Inclusão Digital, disponível em http://www.ong-inclusaodigital.org.br/comunidades.htm, consultado em 4/3/2013). Com esta parceria, o CDI introduziu o tópico da eficiência de energia em seu programa de inclusão digital.

É importante ressaltar desde já que o objetivo de eficiência energética da companhia de distribuição em comunidades de baixa renda também defende a meta de estabilização de relações comerciais: "Desenvolver ações educativas em prol do uso correto e seguro da energia, buscando criar estratégias para aliar a necessidade de consumo à possibilidade de pagamento dos clientes, buscando inibir irregularidades e inadimplências" (LIGHT, 2011, p. 23). Os agentes das comunidades são vistos como importantes intermediários no cumprimento desses diversos objetivos: eles não são apenas responsáveis pelo componente "educacional" do programa, mas também se relacionam diretamente com os clientes em questões diretamente ligadas ao desenvolvimento da relação comercial. Deste 
modo, as medidas "educacionais" do programa caminham lado a lado com o desenvolvimento das relações comerciais. Por exemplo, a fim de se acessar o programa de inclusão digital concretizado pelo CDI - em parceria com a Light -, pedia-se aos moradores que mostrassem suas contas de luz e demonstrassem que seus pagamentos estavam em dia.

Os atores e as dinâmicas apresentadas nesta seção ilustram como as companhias de serviço de eletricidade respondem aos requerimentos de eficiência da ANEEL, através de programas que se destinam a clientes de baixa renda, enquanto desenvolvem o relacionamento com os clientes e promovem a dimensão comercial do acesso ao serviço. A seção seguinte explica os detalhes desta conjuntura, demonstrando como as medidas de eficiência energética, como também os outros instrumentos da regularização do serviço (sociotécnicos e comerciais) articulam-se com objetivo de estabilização das relações comerciais.

\section{Três instrumentos sociotécnicos para a mudança de práticas de consumo de energia elétrica na favela de Santa Marta}

A favela de Santa Marta localiza-se em um morro no bairro de Botafogo, uma das regiões mais ricas da cidade, a zona sul (Figura 1). Trata-se de uma favela de médio porte, com uma população de 3.908 pessoas (1.176 habitações). Se a maior parte dos habitantes da favela de Santa Marta não vive em condições de pobreza $(20 \%$ da população da área tem um perfil socioeconômico considerado pobre (IETS, 2010, IPP-Rio, 2013)), as desigualdades socioeconômicas relativas a Botafogo são significativas: enquanto 38,3\% das moradias de Santa Marta ganham menos de um salário mínimo per capita mensalmente, apenas 5,7\% das moradias de Botafogo possuem este nível salarial (IPP-RIO, 2013). 


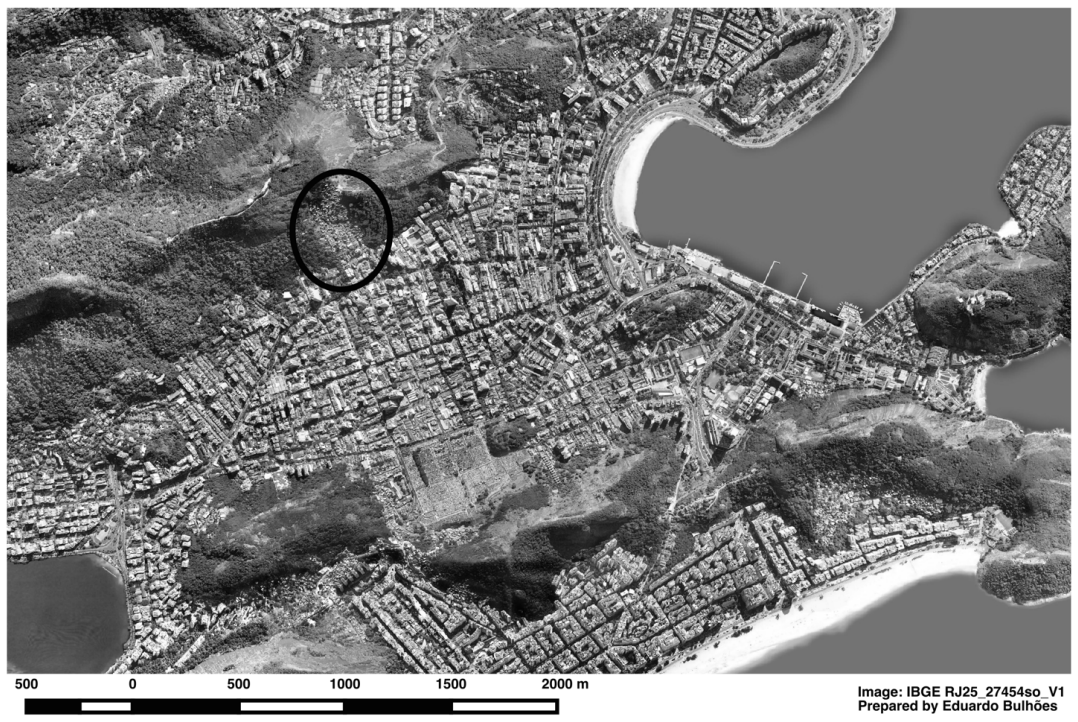

Figura 1: Localização da favela de Santa Marta, Rio de Janeiro. Fonte: IBGE

Tendo sido a primeira favela do Rio de Janeiro a ter uma UPP, estabelecida em 2008, Santa Marta tem sido foco de grandes transformações no que se refere a iniciativas de desenvolvimento urbano e a formalização dos serviços urbanos, especialmente aqueles comerciais.

\section{Modelando as práticas dos consumidores e clientes através de sistemas sociotécnicos}

Tendo começado em 2009, Santa Marta foi a primeira favela em que a Light escolheu introduzir um plano de regularização de energia elétrica. Antes da introdução desse plano, a companhia tinha apenas 73 clientes registrados na área, um número significativamente baixo comparado aos mais de 1.600 clientes registrados no fim do plano de regularização (2010). É, portanto, essencial começar pela observação dos métodos empregados para regularizar a rede de energia elétrica, a fim de entender melhor como tais medidas interagem com outras atividades que têm por objetivo encorajar a economia de energia.

Por meio de mudanças técnicas, tais como a instalação de medidores de energia e a modernização da rede de abastecimento, a companhia regularizou a relação 
comercial para restabelecer uma nova relação contratual com os clientes. Contrariamente ao que se observa na maioria das favelas que não contam com a presença de UPPs, onde os medidores de energia são mecânicos e os cabos elétricos aéreos não são protegidos de fraudes, na favela Santa Marta a antiga rede de distribuição foi substituída por uma rede subterrânea protegida contra fraudes (3,2km de cabos). Dezenove transformadores foram instalados (Figura 2), dobrando a capacidade de distribuição (LIGHT, 2010a), e os antigos postes de madeira foram substituídos por 63 postes de fibra, mais flexíveis e considerados mais apropriados à topografia da favela. Por fim, cada cliente foi equipado com um medidor de energia elétrica individual que se comunica remotamente com a companhia, através de um sistema de telemetria. Essas propriedades técnicas do sistema têm implicações importantes na forma de se relacionar com os clientes, pois não é mais necessário enviar os agentes da empresa para efetuar a leitura do consumo, uma vez que os medidores são lidos remotamente. Além disso, a fim de proteger os medidores de fraudes potenciais, estes não foram instalados individualmente nas moradias, mas em 113 gabinetes blindados, localizados nas ruas (Figura 3), unicamente acessíveis a uma seleção de empregados da companhia (LIGHT, 2010b). Essas medidas técnicas levaram num primeiro momento a melhorias na qualidade do serviço: enquanto em 2009 a interrupção do fornecimento de energia foi de 29 horas, em 2011 este quadro foi reduzido a 8 horas (LIGHT, 2012). Entretanto, a qualidade do serviço ainda não se aproxima da do bairro de Botafogo, que experimentou apenas 2,56 horas de interrupção do fornecimento de energia em 2011 (ANEEL, 2012).

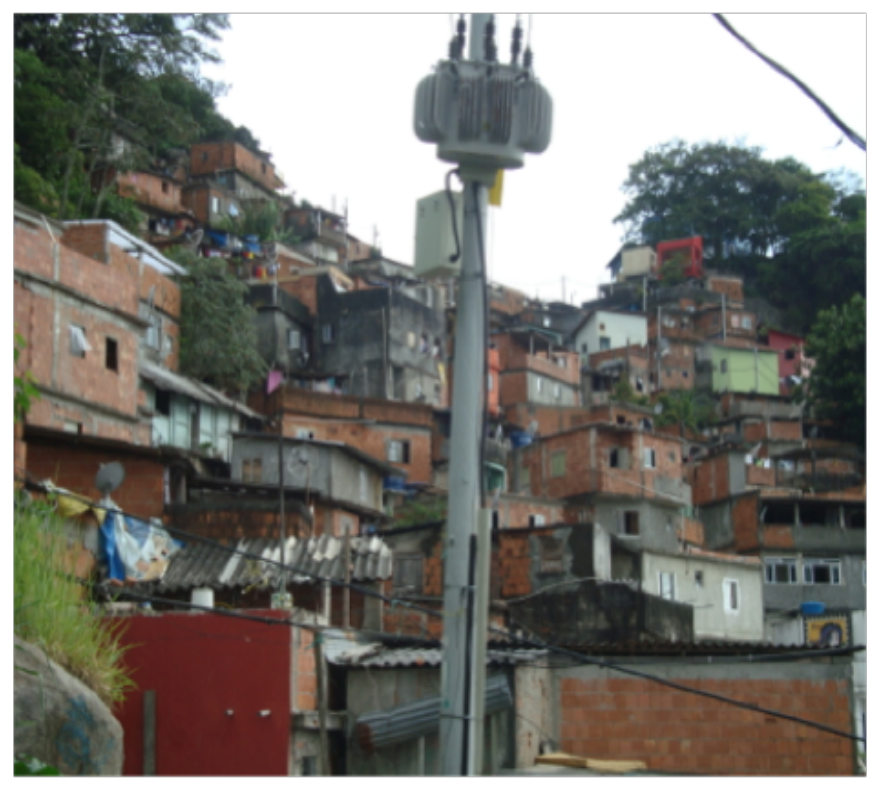

Figura 2: Novos transformadores de energia.

Crédito da imagem: Francesca Pilo' 


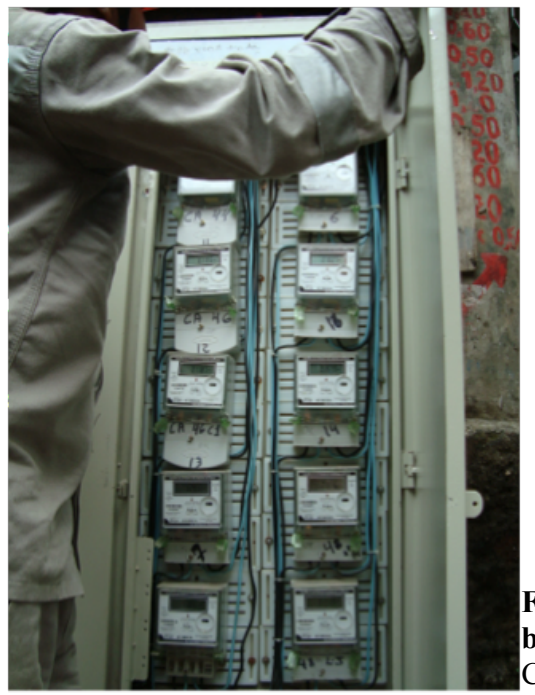

Figura 3: Medidores de energia em gabinete blindado.

Crédito da imagem: Francesca Pilo'

As características deste sistema de fornecimento apontam para o papel atribuído às ferramentas técnicas no estabelecimento da relação com os novos clientes. Como explica Akrich (1987, p. 1), as ferramentas tecnológicas "definem, em sua configuração, uma certa divisão dos mundos físico e social, atribuem papéis a certos tipos de atores humanos e não humanos, ao mesmo tempo que excluem outros, (e) permitem certos tipos de relação entre esses diferentes atores". Neste sentido, os instrumentos sociotécnicos são claramente usados pela companhia no estabelecimento deste novo relacionamento como instrumentos capazes, ao menos parcialmente, de proteger o novo contrato contra possíveis "comportamentos ilícitos" (medidor adulterado etc.). Além disso, na visão da empresa, tais ferramentas também deveriam incentivar uma transformação dos hábitos de consumo, pois a responsabilização pelo pagamento das contas de luz e as mudanças nas práticas de consumo são consideradas como estritamente ligadas/articuladas. Deste modo, tais instrumentos sociotécnicos destinam-se a construir a materialidade de um incentivo a mudanças nas práticas de consumo, primeiramente baseadas na responsabilização pelo pagamento do serviço, concebido nesse contexto como uma forma de comportamento cívico.

\section{A capacidade de pagamento como incentivo às mudanças das práticas de consumo}

Dentro do programa "Comunidade Eficiente", refrigeradores e lâmpadas foram substituídos sem custos em todas as casas que exprimiram o desejo de participar do 
programa. No total, cerca de 7 mil lâmpadas fluorescentes, 653 refrigeradores (42\% das casas) e 490 chuveiros elétricos foram substituídos (LIGHT, 2010a) no Santa Marta. Além disso, foram criadas equipes para informar os residentes sobre os métodos e vantagens da mudança de hábitos de consumo. $\mathrm{O}$ encorajamento da eficiência energética focaliza-se primeiramente na injunção de se reduzir o desperdício. Isso se faz através da promoção da aquisição de aparelhos tecnicamente mais eficazes, o que levaria a uma diminuição do consumo de energia para o mesmo nível de uso. Além dessa vertente técnica, a eficiência energética também é encorajada através de prescrições aos usuários de alterar seus hábitos pessoais diários de consumo de energia por ecogestos: "não deixe a porta da geladeira aberta se não a estiver usando", "apague a luz quando sair do quarto" etc. O incitamento à mudança de hábito é particularmente forte nas favelas, uma vez que as práticas de consumo de energia dos residentes são frequentemente estigmatizadas e reportadas pela mídia como práticas pelas quais a sociedade como um todo paga o preço, na medida em que o custo das perdas comerciais é parcialmente coberto pela companhia através do aumento das tarifas de energia elétrica para todos os consumidores. Contudo, como reconhece o gerente da relação com os investidores da Light, as favelas do Rio de Janeiro são responsáveis por apenas $40 \%$ das perdas comerciais, enquanto o resto é associado à "cidade formal" (FIGO, 2011). De fato, as práticas de desvio da energia elétrica, os famosos "gatos", não são algo específico às favelas, nem estão diretamente relacionados à pobreza: as classes média e alta, assim como os comerciantes, também usam tal prática para reduzir suas contas de luz (ver YACCOUB, 2010).

Como resultado, a mensagem da companhia para seus novos clientes de energia elétrica nas favelas incita não apenas a conservação de energia enfatizando o autocontrole e a responsabilidade individual, mas também as significativas vantagens econômicas que lhes são associadas: praticar a conservação de energia diminuirá o valor das contas de luz. Os métodos empregados pela companhia são, deste modo, permeados por um critério economicamente racional e normativo: economias financeiras em conformidade com uma nova norma ambientalista social. Porém, quando os usuários têm dificuldades no pagamento, notamos que algumas práticas podem ser particularmente alvo de prescrições. Por exemplo, a prática do banho é um tópico comum de aconselhamento, especialmente no caso de grandes famílias: os chuveiros elétricos, cuja contribuição no total da conta de luz de uma moradia pode ser significativamente alta, dependendo de sua utilização (água quente, água morna, água fria), são os aparelhos eletrodomésticos mais comuns nas favelas. Notamos, portanto, que, apesar da narrativa da companhia sobre a conservação de energia elétrica sem debilitar o conforto da moradia, na prática, os limites entre o que é um uso eficiente de energia elétrica, o que é o desperdício de energia e o que são os usos intensos são difíceis de ser definidos, em particular quando a estabilidade da relação comercial parece ameaçada. 


\section{A introdução da relação comercial: uma mudança gradual nos modos de consumo}

O pagamento progressivo do valor da conta de luz foi uma outra maneira de a empresa encorajar o ajuste das práticas de consumo dos clientes à sua capacidade de pagamento. A política comercial para este fim, especificamente criada para as favelas com UPPs, foi introduzida em Santa Marta durante a primeira fase da regularização do projeto. Partindo do pressuposto de que cobrar o custo integral do uso de energia elétrica desde o início do processo de regularização teria tido efeitos negativos tanto para as taxas de adimplência quanto para a aceitabilidade social do projeto, a companhia decidiu introduzir um sistema de cobrança criado para gradualmente habituar os clientes ao pagamento baseado no consumo.

$\mathrm{Na}$ prática, pelos primeiros seis meses, a quantia paga pelos clientes foi estabelecida em um teto de consumo de $79 \mathrm{kWh}$, mesmo que seu consumo estivesse acima de tal teto. Nos meses subsequentes, as linhas de base de consumo pago aumentaram gradualmente, até chegarem a um limite de $200 \mathrm{kWh}$. Apenas as moradias cujo uso de energia elétrica estava abaixo da linha de base estabelecida pagaram por seu real consumo (Figura 4).

\begin{tabular}{|c|c|}
\hline Período & Consumo pago \\
\hline Julho de 2009/Dezembro de 2009 & Até $79 \mathrm{kWh}$ \\
\hline Janeiro/Fevereiro 2010 & Até $100 \mathrm{kWh}$ \\
\hline Março/Abril de 2010 & Até $120 \mathrm{kWh}$ \\
\hline Maio/Junho de 2010 & Até $140 \mathrm{kWh}$ \\
\hline Julho/Agosto de 2010 & Até $160 \mathrm{kWh}$ \\
\hline Setembro/Outubro de 2010 & Até $180 \mathrm{kWh}$ \\
\hline Novembro/Dezembro de 2010 & Até $200 \mathrm{kWh}$ \\
\hline $\begin{array}{l}\text { Depois desta data, a tarifa será proporcional ao real consumo de cada } \\
\text { moradia. }\end{array}$ \\
\hline
\end{tabular}

Figura 4: Método progressivo de cobrança das contas em Santa Marta Fonte: a autora, baseada em pesquisa de campo.

Combinar políticas comerciais e de eficiência energética não é uma prática nova: abordagens similares foram usadas em outros países, em particular na Colômbia e no Canadá, no contexto do serviço de água (FURLONG, 2012; FURLONG; BAKKER, 2011). No caso particular da regularização da energia elétrica, esta visão é então suportada através da ideia de que a mudança dos hábitos de consumo deveria 
ser encorajada graças à combinação de aumentos graduais no valor da conta de luz, medidas de eficiência energética, dentro de um quadro técnico que previne práticas de desvio da energia.

\section{A falta de encorajamento na percepção dos consumidores}

De fato, as recomendações fornecidas pela Light aos clientes para modificar os hábitos de consumo articulam duas clássicas alavancas de política: uma mensagem incisiva de conservação e a ideia de recompensas econômicas resultantes das mudanças de hábito. Como parte da pesquisa da qual resulta este artigo tem como finalidade compreender como os usuários entendem a política de regularização e seus objetivos de eficiência energética, foi realizada uma pesquisa qualitativa com usuários do Santa Marta. A pesquisa foi feita simultaneamente à aplicação da política de cobrança progressiva, discutida na seção anterior. Os resultados ilustram, por um lado, um fraco entendimento da mensagem a respeito da eficiência energética e, por outro lado, a emergência de um contradiscurso por parte dos moradores, em que as ferramentas empregadas pela companhia são criticadas como ineficazes.

\section{"O quanto eu consumo?"}

Uma análise das medidas implementadas pela Light para incentivar a "conscientização" dos usuários quanto aos seus hábitos de consumo permite um entendimento crítico da mensagem da companhia sobre a conservação de energia. Para além do simples aconselhamento dos "ecogestos", discutidos nas seções anteriores, esta seção considera outros instrumentos que não foram especificamente identificados pela companhia de serviço como medidas direcionadas para este fim: a conta de luz e o medidor de energia. Nossa análise afasta-se então da ideia de que é suficiente fornecer informações a respeito do que se entende como "boas práticas de consumo", focando, em vez disso, na materialidade de dois instrumentos específicos - a conta e o medidor - que operam não apenas como mediadores da relação entre usuários e a companhia, mas também como dispositivos que informam tais usuários sobre os níveis e flutuações de seu consumo de energia elétrica.

Como identificado por pesquisadores que trabalham com o tema da energia elétrica no campo das ciências sociais, "a conta de energia costuma funcionar como um intermediário ou um porta-voz inequívoco" (CUPPLES, 2011, p. 943). Porém, os moradores expressaram dificuldades em monitorar seus níveis de consumo. Isso se deve, primeiramente, ao fato de que, na conta de luz dos clientes cujo consumo excedia a linha de base estabelecida, apenas a quantia máxima de consumo 
especificada na linha de base tornava-se um item da conta de luz. No momento da pesquisa, 16 das 25 moradias pesquisadas consumiam mais do que o estabelecido na linha de base (180kWh). Assim, os reais níveis de consumo eram exibidos (em kWh e em valor monetário) apenas nas contas dos clientes cujo consumo estava abaixo da linha de base e, portanto, eram estes os únicos clientes que recebiam informações sobre seus reais níveis de consumo. Neste contexto, é interessante evidenciar também que, durante a pesquisa de campo, a maior parte dos clientes entrevistados não sabia que a conta de luz mostrava apenas o consumo do teto e não o real consumo, o que contribuiu para mal-entendidos a respeito do aumento da conta de luz durante os meses seguintes.

Em segundo lugar, o fato de os clientes não terem acesso direto aos medidores parece também ter enfraquecido o entendimento das dinâmicas de consumo. Furlong mostrou, por exemplo, até que ponto "a maneira como os medidores são utilizados tem implicações diretas em sua eficácia como instrumentos para incentivar os consumidores a controlar sua própria demanda" (FURLONG, 2007, p. 69). Então, apesar de os medidores de energia poderem ser potencialmente uma fonte de informação útil para os consumidores e para as companhias de serviço (FURLONG, 2007), tal função fica comprometida, pois os consumidores não têm acesso direto aos medidores. A fim de remediar esta falta de acesso aos medidores e informar os clientes, a companhia distribuiu dispositivos eletrônicos que, uma vez ligados à tomada, mostrariam o número de $\mathrm{kWh}$ consumidos. Entretanto, esses dispositivos falharam no objetivo pretendido, pois eram tecnicamente defeituosos. Depois da descoberta da falha dos dispositivos, os clientes reclamaram que a companhia decidiu retirá-los sem, porém, propor um mecanismo alternativo para monitorar o consumo. Assim, o vácuo de informação deixado pela conta de luz não foi preenchido por uma explicação suficientemente compreensível a ponto de "pacificar" a situação.

A informação parcial e ambígua dada aos consumidores desencadeou uma série de conflitos entre estes e o provedor de energia. Desprovidos de meios para entender e rastrear seu próprio consumo, os moradores acusaram a companhia de lhes cobrar quantias aleatórias (ver também LORETTI, 2013). A impossibilidade de verificar os níveis de consumo registrados pelo medidor foi condenada por residentes de maneiras diversas. A primeira reclamação foi sobre a necessidade das pessoas de poder controlar seu próprio consumo. Nas palavras de um morador, se "não pudermos verificar/rastrear nosso consumo no medidor, é difícil saber o quanto estamos consumindo" (ENTREVISTA, 2010). A fim de desenvolver a crítica da eficácia de instrumentos usados pela companhia de serviço para encorajar a eficiência energética, os usuários apropriaram-se então da mensagem da companhia sobre "eficiência nas práticas de consumo". Além dessas críticas, os usuários evocaram a recusa ao acesso de medidores como uma expressão da falta de confiança da companhia. Estes argumentos mostram como monitorar o consumo é importante não apenas para sustentar a mensagem sobre a mudança de hábitos de 
consumo, mas também para a construção do entendimento entre os clientes e a companhia.

Pesquisas sobre os vínculos entre infraestruturas e consumo apontam para as dificuldades experimentadas pelos usuários em relacionar os níveis de consumo mostrados nas contas e as práticas de consumo que lhes deram origem (VAN VLIET et al., 2005). Ao mesmo tempo em que as informações precisas e transparentes sobre o consumo não mudam as práticas, no contexto específico do Santa Marta a construção do conhecimento do usuário sobre a relação entre o nível de consumo e suas práticas é porém ainda mais difícil de se vivenciar.

\section{Eficiência energética e política comercial: complementárias ou contraditórias?}

A política comercial implementada pela companhia de energia elétrica, baseada nas linhas de base de consumo e aumentos progressivos no valor do pagamento das contas, parece também ter produzido efeitos contraditórios no objetivo de encorajamento à eficiência energética. Primeiramente porque esse mecanismo aparenta ter neutralizado parcialmente as vantagens econômicas prometidas pela mensagem de encorajamento à mudança de práticas de consumo, no que tange à conservação de energia. De fato, os habitantes esperavam ver nas contas os efeitos dos esforços no controle do consumo, ou seja, a diminuição de seu valor. Porém, isso podia ser verificado somente na conta dos moradores cujo consumo estava abaixo do estabelecido pela linha de base. Para todos os demais, o incentivo econômico era prospectivo, reservado ao período seguinte ao sistema de cobrança progressiva. Percebe-se com isso que, por um lado, existe uma contradição entre a mensagem de promoção de responsabilidade individual e, por outro, um mecanismo que encoraja práticas de consumo uniformes, pois todos pagam pelo mesmo teto de consumo. Portanto, nesta primeira fase, o efeito desta configuração parece ser o enfraquecimento da construção de uma compreensão das ligações entre consumo, gasto e hábitos.

Como resultado, os usuários procuravam outras racionalidades, a fim de estabelecer se o nível de consumo reportado pela companhia era correto e, desse modo, se valia a pena mudar os hábitos. Em geral, os usuários faziam alusão ao número de eletrodomésticos que o vizinho possuía: "De minha parte, tomo cuidado com o que uso, parei de tomar banho todos os dias, mas não faz diferença alguma, porque ainda pago tanto quanto meu vizinho, que tem mais eletrodomésticos que eu", diz uma usuária (ENTREVISTA, 2010). Assim, mais do que os hábitos de consumo, é a posse de aparelhos eletrônicos que conta para os moradores no entendimento dos padrões de consumo. Nesse contexto, o sentido de injustiça evocado pelos moradores ampara-se no fato de pagar o mesmo valor das contas, na relação direta com a posse de aparelhos eletrônicos, e, deste modo, invalida outros 
determinantes que contribuem para definir os perfis de consumo. De maneira geral, se estabelecer uma conexão entre economias de energia e economias financeiras pode ser particularmente difícil, isso parece ainda mais problemático no caso de usuários que instalaram um medidor de energia pela primeira vez, e, deste modo, começaram recentemente o estabelecimento de uma conexão entre consumo e pagamento. Com o sistema de cobrança progressiva, suas primeiras experiências como clientes da companhia de serviço é ver suas contas aumentarem continuamente.

A extensão do sistema de cobrança progressiva para além dos prazos previstos parece mostrar os limites dessa ferramenta enquanto incentivo para reduzir o consumo. Ao mesmo tempo, sob o calendário inicialmente estabelecido pela companhia, a política de cobrança foi definida para terminar ao fim de fevereiro de 2011, mas ainda estava funcionando em dezembro do mesmo ano. Conforme indicado pelo gerente de comunidades da companhia, essa decisão refletia a percepção segundo a qual "os efeitos educacionais esperados ainda não tinham sido atingidos. Um número significativo de clientes continua a consumir mais do que a linha de base. Com esse nível de consumo, é provável que vejamos um aumento na inadimplência" (ENTREVISTA, 2011). A implementação desde 2011 de um projeto de troca de materiais recicláveis por desconto na conta de luz, o Light recicla, que tenho definido de "coprodução da acessibilidade" (PILO', 2016b), mostra particularmente como a regularização abriu a questão da sustentabilidade econômica do acesso ao serviço.

Esta análise ilustra que, apesar da concepção da companhia de serviço sobre a necessidade de abordar as práticas de consumo e as dimensões comerciais como elementos complementares e conectados, o sistema de cobrança gradual pode ser percebido como contraditório na construção experimental da relação entre consumo e despesa, sobretudo se não for acompanhado por outras informações complementares como os níveis efetivos de consumo. Além disso, se as medidas de eficiência energética podem ser um instrumento de redução da pobreza, a integração entre práticas de consumo e lógicas comerciais corre o risco de ser uma ferramenta para estabilizar as relações comerciais e assim visando potencialmente aos mais pobres, para quem um menor consumo de energia pode ser uma consequência de restrições econômicas.

\section{Conclusão}

Este artigo analisou a relação inconstante entre reconfiguração de infraestrutura e política de conservação de energia. Baseia-se em uma análise do programa de eficiência de energia da Light junto a um estudo de caso mais aprofundado do projeto de regularização de energia elétrica na favela Santa Marta, no Rio de 
Janeiro. O artigo mostra como a regularização da energia elétrica e a melhoria das condições físicas de acesso são acompanhadas por medidas específicas que articulam de forma, às vezes, contraditória os objetivos de eficiência energética e de estabilização das relações comerciais. Isso sugere que há implicações sociais e políticas particulares dessas formas de reconfiguração de infraestrutura. Tais habitantes viveram anos com a distribuição irregular de energia elétrica, ainda que não pagassem o custo integral associado a tal distribuição. Contudo, atualmente, uma forma de melhoria de acesso parece encorajá-los ainda mais a aumentar o uso de seus aparelhos eletrônicos. Os habitantes das favelas devem então lidar com diversas contradições. Por um lado, tanto o mercado quanto as políticas públicas encorajam os usuários, apresentados como consumidores, a aumentar o número de aparelhos eletrônicos em suas casas. Enquanto as políticas públicas para acesso ao crédito foram uma ferramenta importante na luta contra a pobreza e na promoção da inclusão social no Brasil (BARONE; SADER, 2009), o mercado promove uma sociedade de consumo baseada em políticas comerciais de crédito, particularmente promovida por lojas que servem às populações de baixa renda. Por outro lado, a regularização da energia elétrica encoraja esta mesma população a mudar seus hábitos de consumo através do conceito de eficiência energética, articulado com a questão da capacidade de pagamento. Finalmente, uma questão continua pendente: quem arca com os esforços da economia da energia? Nas favelas, os hábitos de consumo de dois tipos de famílias podem ser potencialmente alvo de prescrições: as mais pobres, com suas restrições financeiras globais, e a classe média-baixa, que acaba de sair dos ciclos de pobreza e agora possui um acesso relativamente importante aos aparelhos eletrônicos domésticos. Em ambos os casos, a distribuição dos esforços de economia de energia mexe com as desigualdades preexistentes, uma vez que se destina àqueles que de fato estão longe de ser os maiores usuários de energia elétrica.

\section{Referências}

AKRICH, M. (1987) Comment décrire les objets techniques?. Techniques \& Culture. (9). p. 49-64.

BAKKER, K. (2003) Archipelagos and networks: urbanization and water privatization in the South. The Geographical Journal, 169: p. 328-341.

BARONE, F. M., \& SADER E. (2009) Access to credit to fight poverty in Brazil. International Journal of Case Method Research \& Application. XXI (1). p. 19-25.

COUTARD, O. (2008) Placing splintering urbanism: Introduction. Geoforum. 39 (6). p. $1815-1820$.

CUPPLES, J. (2011) Shifting Networks of Power in Nicaragua: Relational Materialisms in the Consumption of Privatized Electricity. Annals of the Association of 
American Geographers. 101 (4). p. 939-948.

DE GOUVELLO, C. \& JANNUZZI G. (2002) Maîtrise de la demande d'électricité et secteurs électriques publics monopolistiques: comparaison France - Brésil. Annales des Mines. p. 31-38.

FAVELA 247 (2014) Santa Marta protesta contra contas da Light. Jornal Brasil 247. [Online]. 26th March 2014. Available from: http://www.brasil247.com/pt/247/favela247/134579/Santa-Marta-protesta-contracontas-da-Light.htm. [Accessed: 27th March 2014].

FIGO, A. (2011) Pacificação de favelas no Rio ajuda a Light ampliar área de cobertura e elevar resultado. Infomoney. [Online]. 24th February. Available from: http://www.infomoney.com.br/mercados/noticia/2024880/pacificacao-favelas-rioajuda-light-ampliar-area-cobertura-elevar-resultado. [Accessed: 3rd March 2014]. FURLONG, K. (2007) Municipal Water Supply Governance in Ontario: Neoliberalization, Utility Restructuring, and Infrastructure Management. A Thesis Submitted in partial fulfilment of the Requirements of University of British Columbia for the Degree of Doctor of Philosophy. Vancouver: University of British Columbia.

. (2012) Mediating the gap between custom, cost-recovery, and "networks": an example from Colombia ». In From networked to post-networked urbanism: new infrastructure configurations and urban transitions. Autun (France), Tuesday 17th to Friday 20th July 2012. p. 25.

FURLONG, K. \& BAKKER K. (2011). Governance and Sustainability at a Municipal Scale: The Challenge of Water Conservation. Canadian Public Policy. 37 (2). p. 219-237.

GELLER, H. S. (2003) Revolução Energética - Políticas para um futuro sustentável. Rio de Janeiro: Relume Dumarà.

GONÇALVES SOARES R., PESSANHA CABRAL M. T. \& MORORÓ MARTINS G. (2016) «Pelo Direito de Permanecer: mobilização política e o acesso a serviços de água e luz nas favelas cariocas no período pós-Estado Novo ». Libertas 15 (2). https://libertas.ufjf.emnuvens.com.br/libertas/article/view/2952.

GRAHAM, S. \& MARVIN S. (2001) Splintering Urbanism: Networked Infrastructures, Technological Mobilities and the Urban Condition. New York: Routledge.

IETS. (2010) Pesquisa nas favelas com unidades de policia pacificadora da cidade do Rio de Janeiro. Resultado Consolidado. Rio de Janeiro: IETS. Available from: http://www.firjan.org.br/data/pages/2C908CE9215B0DC40121793A0FCE1E51.htm

[Accessed: 15th June 2011]

IPP-Rio. (2013) Panorama dos Territórios UPP SANTA MARTA - UPP Social. [Online]. Rio de Janeiro: IPP-Rio. Available from: http://www.riomaissocial.org/territorios/santa-marta/. [Ultima visita: 25 abril 2013] JAGLIN, S. (2005) Services d'eau en Afrique subsaharienne. La fragmentation urbaine en question. Paris: CNRS éditions. 
JAGLIN, S. \& SUBREMON H. (2012) La transition énergétique à l'épreuve des logiques d'usages : le cas des petites classes moyennes au Cap. In Premières journées internationales de sociologie de l'énergie. Toulouse, 25-26 outubro 2012. p. 13.

JANNUZZI, G. (2002) Aumentando a eficiência nos usos finais de energia no Brasil. In Sustentabilidade na Geração e o Uso da Energia no Brasil: os próximos 20 anos. São Paulo, 18-20 de fevereiro 2002. p. 14

KELMAN, J. (2012). The long and winding road. Rio Slums \& the Electric Utility. In Harvard Brazil Studies Program, Harvard, Thursday 19th April. p. 38.

KOOY, M. \& BAKKER K. (2008) Technologies of government: constituting subjectivities, spaces, and infrastructures in colonial and contemporary Jakarta. International Journal of Urban and Regional Research. 32 (2). p. 375-391.

LIGHT. (1980) Eletrificação de favelas no Municipio do Rio de Janeiro. 3 Convenção Brasileira de Assistentes Sociais. Rio de Janeiro : Light

—. (2010a) Relatório de sustentabilidade 2009. Rio de Janeiro: Light.

Light.

. (2010b) Relatório anual responsablidade socioambiental 2009. Rio de Janeiro:

_. (2011) Manual de trabalho educativo. Programa comunidade eficiente, Light. Rio de Janeiro: Light.

. (2012) Relatório de Sustentabilidade 2011. Rio de Janeiro: Light.

LOPES DE SOUZA, M. (2005) O desafio metropolitano: um estudo sobre a problemática socio-espacial nas metrópoles brasileiras. Rio de Janeiro: Bertrand Brasil.

LORETTI, P. (2013) "Atirei o pau no gato": da regularização da energia elétrica aos mecanismos de controle e repressão no contexto de "pacificação" da favela Santa Marta. In XVI Congresso Brasileiro de Sociologia, Salvador de Bahia, 10-13 2013. p. 31.

LORRAIN, D. (ed.) (2011) Métropoles XXL en pays émergents, Paris: Presses de Sciences Po.

McFARLANE, C. (2008) Governing the Contaminated City: Infrastructure and Sanitation in Colonial and Post-Colonial Bombay. International Journal of Urban and Regional Research. 32 (2). p. 415-435.

McFARLANE, C., \& RUTHERFORD, J. (2008) Political Infrastructures: Governing and Experiencing the Fabric of the City », International Journal of Urban and Regional Research. 32 (2). p. 363-374.

PILO', F. (2015) La régularisation des favelas par l'électricité. Un service entre Etat, marché et citoyenneté, tese de doutorado em planejamento urbano ; economia, Université Paris-Est e Universidade Federal Fluminense, pp. 505.

PILO', F. (2016a) Rio de Janeiro, ville (inégalement) branchée? Service d'électricité et divisions de l'espace urbain, Métropolitiques, disponível : http://goo.gl/Afn3tX

PILO', F. (2016b) "Co-producing affordability" to the electricity service: a marketoriented response to addressing inequality of access in Rio de Janeiro's favelas, Urban 
Research \& Practice, DOI: 10.1080/17535069.2016.1154101.

SHOVE, E. (2003) Comfort, cleanliness and convenience: the social organization of normality. Oxford: Berg.

SHOVE, E. \& WALKER, G. (2010) Governing transitions in the sustainability of everyday life. Research Policy. 39 (4). p. 471-476.

SUBREMON, H. (2011) Anthropologie des usages de l'énergie dans l'habitat. Un état des lieux. Paris : Editions Recherche du PUCA.

USAID. (2009) Transforming electricity consumers into customers: case study of a slum electrification and loss reduction project in São Paulo, Brazil. Washington D.C.: Agency for International Development.

VAN VLIET, B., CHAPPELLS, H. \& SHOVE, E., (2005) Infrastructures of consumption: environmental innovation in the utility industries. London: Earthscan Publications.

YACCOUB, H. (2010) Atirei o pau no "gato". Uma analise sobre consumo e furto de energia elétrica (dos "novos consumidores") em um bairro popular de Sao Gonçalo $R J$. Programa de Pós-graduação em Antropologia, Niteroi: Universidade Federal Fluminense.

ZELEM, M-C. (2010) Politique de maîtrise de la demande d'énergie et résistances au changement. Une approche socio-anthropologique. Paris: L'Harmattan, Logiques sociales.

Data de submissão: 07/09/2016.

Data de aceite: 22/12/2016. 